\title{
ТЕРРИТОРИЯ ОПЕРЕЖАЮЩЕГО РАЗВИТИЯ КАК ФАКТОР ПОВЫШЕНИЯ ИНВЕСТИЦИОННОЙ ПРИВЛЕКАТЕЛЬНОСТИ МОНОГОРОДА
}

В статье рассмотрены перспективы и проблемы реализации государственной программы по созданию территории опережаючего развития (ТОР) в моногородах. Проведен анализ предоставляемых льгот для резидентов при реализации инновационной стратегии развития территорий с нестабильным сочиально-экономическим положением на муниципальном уровне (в г. Невинномысск Ставропольского края). Определены направления совериенствования программы по комплексному развитию монопрофильных городов, позволяюиие нивелировать выявленные проблемы.

Ключевые слова: моногород, территория опережсоюего развития, инвестиции, сочиально-экономическое положение.

\section{Anna Lomakina \\ TERRITORY OF SUSTAINABLE DEVELOPMENT AS A FACTOR INCREASING INVESTMENT ATTRACTIVENESS MONTY CITY}

The article considersthe perspectives and problems of the implementation of the state program for the creation of a territory for advanced development (TOR) in single-industry towns. The analysis of the provided benefits for residents in the implementation of an innovative development strategy for territories with an unstable social and economic situation at the municipal level (in Nevinnomyssk, Stavropol Territory) was analyzed. The directions of perfection of the program on integrated development of mono-profile cities have been determined, which make it possible to level out the identified problems. situation.

Key words: monotown, territory of advanced development, investments, social and economic

Bвedenue /Introduction. Моногорода на протяжении многих десятилетий являются важной составляющей российской экономики, целые поколения людей связывают свою жизнь с определенным градообразующим предприятием. Прообразом современных моногородов являются поселения, которые формировались вокруг крупных мануфактур еще позапрошлом столетии. В XX веке их количество в нашей стране стремительно увеличивалось, люди приезжали на «стройки века», создавали семьи и оставались на постоянное место жительства. По состоянию на 2017 г. число городов РФ увеличилось до 1113 и около 400 из них соответствуют критериям моногорода, в них проживает порядка 40 \% населения России. Таким образом, экономика монопрофильных городов определяет уровень благосостояния весомой части граждан страны, а следовательно, и привлекательность государства для проживания людей на его территории.

Maтериалы и методы / Materials and methods. Теоретической и методологической основой исследования послужили фундаментальные и прикладные исследования современных отечественных и зарубежных авторов в области экономики, тематические публикации в периодической печати, посвященные проблемам повышения инвестиционной привлекательности регионов. В ходе работы использовались следующие методы: обобщение, сравнение, логический анализ, синтез, индукция и т. д.

Pезультаты и обсуждение /Results and discussion. Кризисные проявления последних десятилетий привели к необ́ходимости искать новые инструменты регулирования социально-экономического положения нашей страны. 
В связи с этим в июле 2016 г. Совет по стратегическому развитию и приоритетным проектам при Президенте России утвердил 11 национальных проектов, призванных способствовать экономическому росту и повышению качества жизни и благосостояния россиян. Одно из этих стратегических направлений - модернизация моногородов.

Главные задачи проекта:

1) диверсификация экономики моногородов;

2) создание условий для привлечения инвестиций и развития бизнеса;

3) создание новых рабочих мест;

4) комфортные условия жизни в моногородах.

До конца 2018 г. в рамках проекта предусматривается: создать не менее 200000 рабочих мест, не связанных с градообразующим предприятием; привлечь 317 млрд руб. инвестиций в основной капитал; значительно улучшить качество городской среды [12].

Ежегодно официальный перечень монопрофильных муниципальных образований, где более трёх тысяч жителей и на работников одной организации приходится 20 \% общей среднесписочной численности территории, актуализируется, и ранее их делили на три категории (таблица 1).

Таблица 1

Распределение моногородов по социально-экономической ситуации

\begin{tabular}{|c|c|c|c|}
\hline Зона & $\begin{array}{c}\text { Социально-экономическое } \\
\text { положение }\end{array}$ & $\mathbf{2 0 1 4}$ & $\mathbf{2 0 1 7}$ \\
\hline «Красная» & наиболее сложное & 75 & 94 \\
\hline «Желтая» & есть риски ухудшения & 149 & 154 \\
\hline «Зеленая» & стабильное & 89 & 71 \\
\hline
\end{tabular}

Позиция в зонах оценивается по ряду основных критериев в зависимости от возможных рисков снижения показателей их социально-экономического положения. Соответственно, существует очередность на получение финансовой поддержки. Официальной структурой поддержки городов «одного предприятия) является некоммерческая организация «Фонд развития моногородов», учрежденная в октябре 2014 г. в качестве оператора бюджетных средств. Его учредителем стал Внешэкономбанк, вложивший 16,4 млн рублей. Всё остальное финансирование, в том числе на поддержку моногородов и хозяйственную деятельность самого фонда, идёт из федерального бюджета. Первыми на поддержку фонда претендовали монопрофильные муниципальные образования из «красной зоны риска» с наихудшим социально-экономическим состоянием. Согласно экспертным оценкам, в первоочередниках числился почти каждый третий из 313 моногородов.

В настоящее время все монопрофильные муниципалитеты в равной степени претендуют на помощь Фонда развития моногородов, поскольку отменена их градация по сложности социально-экономического положения. С отменой градации одним из первых внеочередников стал город Невинномысск Ставропольского края.

Невинномысск является стратегическим транспортным коридором Ставропольского края. Население города составляет 117,7 тыс. человек, в том числе экономически активного населения 84,3 тыс. человек. Промышленность города, помимо местных производителей, представлена и крупными российскими холдингами, продукция которых широко известна на территории РФ и за ее пределами: Минерально-химическая компания «ЕвроХим», компания «Арнест».

Постановлением Правительства РФ от 22 декабря 2017 г. № 1606 в границах города Невинномысска создана территория опережающего социально-экономического развития «Невинномысск» (далее ТОСЭР - «Невинномысск»). Срок ее работы составляет 10 лет с возможностью продления на 5 лет. Условия получения статуса резидента: инвестиционные вложения в первый 
год осуществления проекта от 5 млн рублей (без учета НДС); создание не менее 20 рабочих мест в первый год осуществления проекта. Для резидентов ТОСЭР - «Невинномысск» установлен перечень из 23 видов экономической деятельности, на которые распространяется особый правовой режим предпринимательской деятельности (таблица 2).

Таблица 2

Льготы для резидентов ТОСЭР - «Невинномысск»

\begin{tabular}{|c|c|c|c|}
\hline Вид платежа & $\begin{array}{c}\text { Первые } 5 \text { лет реализа- } \\
\text { ции инвестиционного } \\
\text { проекта }\end{array}$ & $\begin{array}{c}\text { Последующие годы } \\
\text { инвестиционного } \\
\text { проекта }\end{array}$ & $\begin{array}{c}\text { Стандартная ставка } \\
\text { налога }\end{array}$ \\
\hline Налог на прибыль & не более $5 \%$ & не менее $10 \%$ & $20 \%$ \\
\hline Налог на имущество & $0 \%$ & $0 \%$ & $2,2 \%$ \\
\hline Налог на землю & $0 \% *$ & $0 \% *$ & $0,01-1,5 \%$ \\
\hline $\begin{array}{l}\text { Плата за аренду } \\
\text { земельных участков }\end{array}$ & $0 \% *$ & $0 \% *$ & $7 \%$ \\
\hline $\begin{array}{l}\text { взносы в: } \\
\text { Пенсионный Фонд РФ } \\
\text { Фонд социального } \\
\text { страхования РФ } \\
\text { Фонд обязательного } \\
\text { медицинского } \\
\text { страхования РФ }\end{array}$ & $\begin{array}{r}6 \% \\
1,5 \% \\
0,1 \%\end{array}$ & $\begin{array}{r}6 \% \\
1,5 \% \\
0,1 \%\end{array}$ & $\begin{array}{l}22 \% \\
2,9 \%\end{array}$ \\
\hline
\end{tabular}

"по решению местных властей, в настояиее вреия готовится соответствуюиий нориативный правовой акт [13, 14].

Также установлен перечень видов деятельности, которыми на территории ТОСЭР не разрешается заниматься:

1) добычей сырой нефти, а также природного газа;

2) предоставлять услуги в области добычи нефти, а также природного газа;

3) вести деятельность по трубопроводному транспорту;

4) заниматься производством нефтепродуктов;

5) оптовой и розничной торговлей;

6) лесозаготовкой;

7) операциями с недвижимым имуществом;

8) видами экономической деятельности, в которых занято не менее $20 \%$ среднесписочной численности сотрудников всех предприятий моногорода.

Создание ТОСЭР «Невинномысск» будет способствовать диверсификации экономики города, позволит уменьшить зависимость от градообразующих для муниципалитета химических предприятий «Невинномысский Азот» и «Арнест», увеличить инвестиционную привлекательность города, в частности планируется к 2020 году создать от 3,5 до 5 тыс. постоянных рабочих мест и привлечь инвестиции свыше 60 млрд рублей. В рамках создания ТОСЭР краевым правительством подписаны рамочные соглашения с инвесторами о реализации 13 инвестиционных проектов. Планируется строительство II и III очередей Невинномысского радиаторного завода, молочного комбината, мукомольного комплекса, завода по переработке гречихи, кондитерской фабрики, завода по производству биотоплива из семян рапса. Запланировано строительство стеклотарного завода, организация производства светоизлучающих диодов, разработка технологии и организация серийного выпуска кристаллов искусственного сапфира больших и сверхбольших диаметров. А также производство зарядных станций для электромобилей, металлической упаковки, текстильных тканей, трикотажных изделий и одежды [3]. 
Первым статус резидента ТОСЭР - «Невинномысск» получил ООО «Казьминский молочный комбинат», который об̆ъединил шесть производителей молочной продукции. Объем инвестиций в создание предприятия превысил 750 млн рублей. Молочный комбинат был возведен при финансовой поддержке Юго-Западного банка ПАО Сбербанк. «Поддержка предприятий агропромышленного комплекса - одно из приоритетных направлений деятельности банка. Ключевым драйвером роста инвестиционной активности в Ставропольском крае в последние годы становится сельскохозяйственная отрасль, на долю которой приходится более $25 \%$ всего финансирования $[4,11]$.

Стоимость инвестпроекта составила 750 млн рублей. Данные инвестиции оправданы, ведь статус резидента ТОСЭР дает бизнесу ощутимые преимущества. Но и отдача от «Казьминского» огромная: на предприятии создано 194 новых рабочих места. Мощность переработки завода - до 100 тыс. т молока в сутки. Два года велись работы по проектированию, строительству, пуско-наладке заводских мощностей с учетом инновационной направленности [1].

Предприятие впечатляет: оно построено с нуля в промышленной зоне города Невинномысска, рядом находятся автотрасса и железная дорога. Ведь сырье (молоко) сюда будут привозить от пяти предприятий Кочубеевского района: «Колос», «Полярная звезда», «Кубань», «Казьминский» и племзавод имени Чапаева. Таким образом, «Казьминский молочный комбинат» стал не только первым реальным резидентом, но и примером успешной сельскохозяйственной кооперации в Ставропольском крае, для которого характерна некая раздробленность между производителями и переработчиками [10].

Создание крупных формирований в условиях сложившейся экономической ситуации в сельском хозяйстве представляется наиболее перспективным. Оно ведет к увеличению объемов производства, сокращению себестоимости продукции и снижению цен реализации, вовлечению других предприятий (транспортных, информационных) для рационального использования имеющихся ресурсов $[2,7]$.

Модернизация и увеличение объемов производства заранее заложены в проект завода. Завод стал важнейшей частью агропромышленного холдинга, который обеспечивает все этапы производства и поставки молока. Благодаря продуманной структуре, завод работает без сбоев и остановок, круглосуточно поставляя на рынок края и страны высококачественную молочную продукцию. В современных условиях успешно могут развиваться лишь те предприятия, которые своевременно выявляют изменение общественных потребностей в молочной промышленности $[6,8]$. Поэтому здесь будет производиться широкий ассортимент молочной продукции, включая выдержанные сыры, - до 1,5 тысяч тонн в год, йогурты по термостатной технологии, сохраняющие полезную микрофлору.

Однако жителям Невинномысска вряд ли стоит рассчитывать на быстрое социально-экономическое развитие. Как показывает опыт льготы и преференции бизнесу - еще не залог быстрого финансового подъема территории. И потребуется немало лет, чтобы экономическое чудо все же произошло, для этого необходимо применять многоцелевой подход при оценке инновационно-инвестиционной деятельности [9].

Невинномысск называют промышленной столицей Ставропольского края. Проведенное городскими властями в начале 2017 года исследование показало, что с 2010 года население Невинномысска сократилось на 20 тысяч человек, а, согласно социологическим опросам, еще $65 \%$ жителей в возрасте от 18 до 35 лет готовы покинуть город.

Одна из главных проблем реализации государственной программы по созданию ТОСЭР это отсутствие инфраструктуры в городе, он мрачный, неприглядный. На это во многом повлияла и частая смена руководства города - за семь лет поменялись четыре главы, и системные административные ошибки. Однако работа и в этом направлении уже ведется. Так, в 2017 г. по реализации муниципальной целевой программы «Комфортный город» приведены в порядок центральные 
улицы города: отремонтировано дорожное покрытие, установлены новые бордюры, ограждения, разделяющие направление движения транспорта. Проведены работы по укладке тротуарной плитки, осуществлен монтаж новых остановочных пунктов, установлены новые фонари и светофоры.

Создание ТОСЭР в Невинномысске - это далеко не первый шаг в направлении диверсификации экономики для стимулирования промышленности в городе и привлечения инвестиций. Так, в 2010 году здесь открыли региональный индустриальный парк (РИП). За почти семь лет работы РИП показал впечатляющие результаты - первая очередь парка практически заполнена, идет строительство второй очереди. На территории РИП сейчас работают 12 компаний, предлагающих более трех тысяч рабочих мест.

Регион предоставил резидентам на конкурсной основе получить бесплатно земельный участок с сетями (электричеством, газом, водой), а также особые налоговые условия. Инвесторы заинтересовались и начали строить предприятия. Невинномысск - это традиционно город химиков, но сегодня здесь есть и сталелитейщики. Программу поддержки моногородов, которая дает большие возможности инвесторам, привязали к региональному парку Невинномысска, в итоге площадка стала более интересна для предпринимателей. Поэтому, несмотря на зафиксированный отток населения, в администрации муниципального образования рассчитывают, что в перспективе начнется обратная миграция - на новые предприятия будут приезжать рабочие, а значит, покупать в городе жилье. Увеличится и сбор НДФЛ - в 2017 г. сбор налога на доходы физлиц составляет около 310 млн рублей в год, в следующем году планируется получить в бюджет около 360 млн руб. Невинномысский региональный индустриальный парк в прошлом году занял первое место в России по качеству его подготовки и вовлечению бизнеса.

На ТОСЭР в Невинномысске также возлагают большие надежды. Улучшенный льготный режим будет способбствовать строительству новых производств, развитию малого и среднего бизнеса. Увеличенный городской бюджет повысит качество жизни невинномысцев, позволит благоустроить город. Но пока приходится признать, что за шесть лет работы одного из лучших региональных индустриальных парков в России ситуация в Невинномысске кардинально не изменилась.

Из 11 технопарков Ставропольского края «Невинномысск» - единственный эффективно работающий и имеющий достаточное количество резидентов. Но надо понимать, что срок окупаемости проектов, реализуемых в технопарках, обычно составляет не менее пяти-семи лет. Тем более что сейчас у предприятий есть проблемы с оборотными средствами, поэтому они вынуждены производить продукцию малыми партиями, соответственно, окупаемость затягивается. Из-за этого и льготы в виде сниженного налога на прибыль не так эффективны. Требуется применение и других экономических мер стимулирования инвестиционной привлекательности, например, применение льготного кредитования, а также широко используемого в зарубежных странах аутсорсинга.

Среди явных проблем необходимо выделить и риски, связанные с развитием промышленности, так как оборудование - это все опасные объекты как с точки зрения охраны труда, так и с экологического аспекта. Поэтому необходимо страховать производство, и с проверками регулярно приходят надзорные структуры [5]. То есть ответственность у промышленников большая, а штрафы высокие.

Создание ТОСЭР - хорошая идея, но в крае не все могут выехать в Невинномысск на работу. Поэтому опыт данного технопарка необходимо распространять и на другие территории, чтобы не собирать всех инвесторов в одном месте. Такая гиперцентрализация тоже будет проблемой со временем. Создание ТОСЭР на территории муниципального образования с градообразующим предприятием является мощным инструментом государственной поддержки и способствует совершенствованию системы местного самоуправления в период экономического кризиса и посткризисный период. Правительство края должно работать над тем, чтобы в остальных технопарках региона заработала инфраструктура. 
Заключение / Conclusion. Таким образом, значение создания ТОСЭР заключается в стремлении сформировать в отдаленных локализациях страны мощные экономические центры. Именно на таких территориях в перспективе подразумевается активный рост и развитие социально-экономической жизни. Но при этом при создании ТОСЭР особое внимание нужно уделять рассмотрению проектов, оценивать все риски, экономическую и экологическую обоснованность проектов. Решение проблем моногородов важно осуществлять на всех трех уровнях власти и управления государством: национальном, региональном, местном. При этом важно использовать как административные (законы, постановления, приказы, распоряжения), так и экономические методы управления (льготная система кредитования, аутсорсинг и др.).

\section{ЛИТЕРАТУРА И ИНТЕРНЕТ-РЕСУРСЫ}

1. Васюкова В. А., Воробьева И. В. Инновационное предпринимательство на основе развития бизнес-инкубатора // Экономическое развитие России: ловушки, развилки и переосмысление роста: материалы Международной научно-практической конференции. Невинномысск, 2017. С. 119-122. URL: https://elibrary.ru/item.asp?id=29088342

2. Дементьева А. Н. Интеграция как инструмент повышения эффективности предпринимательских структур // Достижения науки и техники АПК. 2006. № 6. С. 55-56.

3. Информационный портал «Региональное законодательство» [Электронный ресypc]. URL:http:// www.regionz.ru

4. Кирпанев В. П. Проблемы стимулирования инвестиционной активности в промышленности // Вестник Университета (Государственный университет управления). 2011. № 4. С. 191-192.

5. Лихонина О. А. Особенности управления сельскохозяйственными рисками с использованием системы интегрированного страхования // Управление в социальных и экономических системах. 2015. № 24. C. $83-84$.

6. Ломакина А. Н. Инновационные стратегии развития - инструмент повышения эффективности деятельности предпринимательских структур в молочной промышленности // Концепт: научно-методический электронный журнал. 2013. Т. 3. С. 2951-2955. [Электронный ресурс]. URL: http://e-koncept. $\mathrm{ru} / 2013 / 53596 . \mathrm{htm}$.

7. Ломакина А. Н. Развитие предпринимательства на основе создания финансово-промышленной группы // Трансформация региона в условиях глобализации экономического развития: сб. научных трудов по материалам Международной научно-практической конференции. М.: Илекса, 2013. C. 76-80. URL: https://elibrary.ru/item.asp?id=23476410

8. Ломакина А. Н. Тенденции развития предпринимательства на региональном молокопродуктовом рынке Ставропольского края // Молодежная наука в развитии регионов: материалы II Всероссийской конференции студентов и молодых ученых с международным участием / под ред. Н. П. Нечаева. Пермь: Пермский национальный исследовательский политехнический университет, 2012. С. 439-442.

9. Манчук Е., Коваленко Н., Ломакина А. Теоретико-методологические аспекты исследования системного подхода на основе принципов оценки экономической эффективности инновационно-инвестиционных проектов малых предприятий // Предпринимательство. 2014. № 6. С. 140-148.

10. Манчук Е., Коваленко Н., Ломакина А. Проблемы экономического развития региона и способы их преодоления в современных условиях (на примере Ставропольского края) // Предпринимательство. 2015. № 2. C. 114-125.

11. Остапенко Е. А., Шамрина С. Ю. Инвестиционный инструмент обеспечения устойчивого развития социально-экономических подсистем с учетом их специализации // Экономика. Бизнес. Банки. 2015. № 2 (11). С. 104-111.

12. Официальный сайт «Портал госпрограмм РФ» [Электронный ресурc]. URL: https://programs.gov.ru/

13. Официальный сайт «Дума города Невинномысск» [Электронный pecypc]. URL: http://dumanev.ru

14. Официальный сайт «Налоговая инспекция» [Электронный ресурc]. URL: https://nalogovaya.ru/ stavropolskiy-kray 


\section{REFERENCES AND INTERNET RESOURCES}

1. Vasyukova V. A., Vorob'yeva I. V. Innovatsionnoye predprinimatel'stvo na osnove razvitiya biznesinkubatora (Innovative entrepreneurship based on the development of a business incubator) // Ekonomicheskoye razvitiye Rossii: lovushki, razvilki i pereosmysleniye rosta: materialy mezhdunarodnoy nauchno-prakticheskoy konferentsii. Nevinnomyssk, 2017. Pp. 119-122. URL: https://elibrary.ru/item. asp?id=29088342

2. Dement'yeva A. N. Integratsiya kak instrument povysheniya effektivnosti predprinimatel'skikh struktur (Integration as a tool to increase the effectiveness of entrepreneurial structures) // Dostizheniya nauki i tekhniki APK. 2006. No 6. Pp. 55-56.

3. Informatsionnyi portal «Regional'noye zakonodatel'stvo» [Elektronnyi resurs]. URL: http://www.regionz.ru

4. Kirpanev V. P. Problemy stimulirovaniya investitsionnoy aktivnosti $v$ promyshlennosti (Problems of stimulating investment activity in industry) // Vestnik Universiteta (Gosudarstvenny yuniversitet upravleniya). 2011. No 4. Pp. 191-192.

5. Likhonina O. A. Osobennosti upravleniya sel'skokhozyaystvennymi riskami s ispol'zovaniyem system yintegrirovannogo strakhovaniya (Features of management of agricultural risks with the use of the integrated insurance system) // Upravleniye v sotsial'nykh i ekonomicheskikh sistemakh. 2015. No 24. Pp. 83-84.

6. Lomakina A. N. Innovatsionnyye strategii razvitiya - instrument povysheniya effektivnosti deyatel'nosti predprinimatel'skikh struktur v molochnoy promyshlennosti (Innovative development strategies - a tool to increase the effectiveness of entrepreneurial structures in the dairy industry) // Kontsept: nauchnometodicheski yelektronnyy zhurnal. 2013, T. 3. Pp. 2951-2955. [Elektronnyy resurs]. URL: http:// e-koncept.ru/2013/53596.htm.

7. Lomakina A. N. Razvitiye predprinimatel'stva na osnove sozdaniya finansovo-promyshlennoy gruppy (Development of entrepreneurshipbased on the creation of a financial and industrial group) // Transformatsiya regiona $\mathrm{v}$ usloviyakh globalizatsii ekonomicheskogo razvitiya: sbornik nauchnykh trudov po materialam Mezhdunarodnoy nauchno-prakticheskoy konferentsii. M.: Ileksa, 2013, Pp. 76-80.

8. Lomakina A. N. Tendentsii razvitiya predprinimatel'stva na regional'nom molokoproduktovom rynke Stavropol'skogo kraya (Tendencies of entrepreneurship development in the regional dairy products market of the Stavropol Territory) // Molodezhnaya nauka v razvitii regionov: materialy II Vserossiyskoy konferentsii studentov i molodykh uchenykh s mezhdunarodnym uchastiyem / pod red. N. P. Nechayeva. Perm': Permskij nacional'nyj issledovatel'skij politekhnicheskij universitet, 2012. Pp. 439-442.

9. Manchuk E., Kovalenko N., Lomakina A. Theoretical and methodological aspects of research of the system approach on the basis of principles of economic efficiency estimation of small enterprises innovativeinvestment projects (Theoretical and methodological aspects of the research of the system approach on the basis of the principles of economic efficiency evaluation of innovation and investment projects of small enterprises) // Predprinimatel'stvo. 2014. No 6. Pp. 140-148.

10. Manchuk Ye., Kovalenko N., Lomakina A. Problemy ekonomicheskogo razvitiya regiona i sposoby ikh preodoleniya v sovremennykh usloviyakh (na primere Stavropol'skogo kraya) (Problems of economic development of the region and ways to overcome them in modern conditions (the example of the Stavropol Territory)) // Predprinimatel'stvo. 2015. No 2. Pp. 114-125.

11. Ostapenko Ye. A., Shamrina S. YU. Investitsionnyy instrument obespecheniya ustoychivogo razvitiya sotsial'no-ekonomicheskikh podsistem $\mathrm{s}$ uchetom $\mathrm{ikh}$ spetsializatsii (Investment tool for sustainable development of socio-economic subsystems, taking into account their specialization) // Ekonomika. Biznes. Banki. 2015. No 2 (11). Pp. 104-111.

12. Ofitsial'nyi sait «Portal gosprogramm RF» [Elektronnyi resurs]. URL: https:// programs.gov.ru

13. Ofitsial'nyi sait «Duma goroda Nevinnomyssk» [Elektronnyi resurs]. URL: http:// dumanev.ru

14. Ofitsial'nyi sait «Nalogovaya inspektsiya» [Elektronnyi resurs]. URL: https:// nalogovaya.ru/stavropolskiy-kray

\section{СВЕДЕНИЯ ОБ АВТОРЕ}

Ломакина Анна Николаевна, кандидат экономических наук, доцент кафедры гуманитарных и математических дисциплин Невинномысского технологического института (филиал) Северо-Кавказского федерального университета. E-mail: annancfu@yandex.ru 


\section{INFORMATION ABOUT AUTHOR}

Lomakina Anna, Candidate of Economic Sciences, associate Professor of the Department of Humanities and Mathematical Disciplines of the Nevinnomyssk Technological Institute (branch) of North-Caucasus federal university E-mail: annancfuayandex.ru

\section{Парахина Валентина Николаевна, Шалашаа Заур Иванович, Устаев Рустам Мерзеферович}

\section{К ВОПРОСУ О РАЗВИТИИ ГОСУДАРСТВЕННО-ЧАСТНОГО ПАРТНЕРСТВА В РОССИИ И В АБХАЗИИ}

В статье представлены общие признаки государственно-частного партнерства, отличаюицеся от аналогичных форм отночений государства и частного бизнеса. Охарактеризованы модели государственно-частного партнерства, соответствуюиие определенньм челям развития. Показаны и описаны общие механизиы государственно-частного партнерства. Исследована спечифика развития государственно-частного партнерства в Российской Федерации с выделением суиествуюиих недостатков и приоритетов в развитии. Подчеркивается важность разработки и использования механизлов государственно-частного партнерства в экономике Абхазии, направленного на совериенствование прочессов инвестирования, привлечения дополнительных ресурсов и улучиения качества предоставляемых услуг в отраслях сочиально-культурной сферы. Выделяются потенциальные возможности развития в сфере государственно-частного партнерства в рамках международного сотрудничества России и Абхазии.

Ключевые слова: государственно-частное партнерство, модель, развитие, Россия, Абхазия.

\section{Valentina Parakhina, Zaur SHalashaa, Rustam Ustaev \\ THE QUESTION OF THE DEVELOPMENT OF PUBLIC-PRIVATE PARTNERSHIP IN RUSSIA AND ABKHAZIA}

The article presents the General features of public-private partnership, which differ from similar forms of relations between the state and private business. The models of public-private partnership corresponding to certain development goals are characterized. The General mechanisms of public-private partnership are shown and described. The specifics of the development of public-private partnership in the Russian Federation with the allocation of existing shortcomings and priorities in the development. The importance of the development and use of mechanisms of public-private partnership in the economy of Abkhazia aimed at improving the processes of investment, attracting additional resources and improving the quality of services in the sectors of social and cultural sphere is emphasized. Potential opportunities for development in the sphere of public-private partnership in the framework of international cooperation between Russia and Abkhazia are highlighted.

Key words: public-private partnership, model, development, Russia, Abkhazia.

Bведениe/Introduction. В последние годы в большинстве стран мира с рыночной экономикой в качестве реальной альтернативы приватизации объектов большое значение стала приобретать концепция государственно-частного партнерства (ГЧП). Сам термин «государственно-частное партнерство» появился в начале 80-х годов для характеристики особых государственно-частных отношений в сфере производственной и социальной инфраструктуры [10]. Это прежде всего касалось автомобильных и железных дорог, аэропортов, морских портов, энергетических сетей, коммунального хозяйства, телекоммуникаций, объектов образования, здравоохранения и культу- 